NBER WORKING PAPER SERIES

\title{
COMOVEMENTS IN STOCK PRICES AND
}

COMOVEMENTS IN DIVIDENDS

\author{
Robert J. Shiller
}

Working Paper No. 2846

\author{
NATIONAL BUREAU OF ECONOMIC RESEARCH \\ 1050 Massachusetts Avenue \\ Cambridge, MA 02138 \\ February 1989
}

The author is indebted to Bryan Allworthy, George Bulkley, Peter Garber; Fumiko Konya, Rudolph Richter, Anna Schwartz, Ian Tonks and many others for help with data collection. Thomas Schwingeler provided research assistance. This research was supported by the National Science Foundation. This paper is part of NBER's research program in Financial Markets and Monetary Economics. Any opinions expressed are those of the authors not those of the National Bureau of Economic Research. 


\title{
February 1989 \\ COMOVEMENTS IN STOCK PRICES AND \\ COMOVEMENTS IN DIVIDENDS
}

NBER Working Paper \#2846

\begin{abstract}
Simple efficient markets models imply that the covarlance between prices of speculative assets cannot exceed the covariance between their respective fundamentals unless there is positive information pooling. Positive information pooling occurs when there is more information, in a sense defined here, about the aggregate of the fundamentals than there is about the individual fundamentals.

With constant discount rates, the covariance between prices (detrended by dividing by a moving average of lagged dividends) in the $U$. $K$. and the $U$. S. exceeds the covariance of the measure of fundamentals, and there is no evidence of positive Information pooling. Regression tests of forecast errors in one country on a real price variable in another country show significantly negative coefficlents. When the present value formula uses short rates to discount, there is less evidence of excess comovement.
\end{abstract}

Robert J. Shiller Cowles Foundation Yale University 30 Hillhouse Avenue New Haven, CT 06520 


\section{Introduction}

Stock price Indexes are correlated across countries. Can such correlations be justified in terms of correlation across countries in fundamentals under efficlent markets? In real dividends? or in real Interest rates?

For example, on October 19-20, 1987 the level of stock prices in all the major stock markets of the world made simflar spectacular drops. Some observers have stated that it seems unlikely that negative information about fundamentals appeared in all these diverse economies during the crash. The crash is, however, only one episode. Can stock price comovements overall be justified by comovements in dividends and real interest rates? ${ }^{2}$

Figure 1 upper panel shows real dividend indexes for the $U$. $K$ and the U. S, for years 1919 to 1987. Figure 1 lower panel shows the corresponding real price indexes for the U, K. and the U. S. for the end of each year. (These data, which are the basis for the empirical work here, are defined below.) There is some apparent resemblance between the dividend series as well as between the price series. But simple comparisons of such plots do not enable us to ask whether prices covary more than would be Implied by efficient markets models. More theoretical apparatus is needed.

${ }^{2}$ Pindyck and Rotemberg have analyzed whether there is excess comovement of commodity prices relative to co-movements in fundamentals. Their analysis is rather different, in that they did not directly measure the fundamentals. 


\section{The Efficient Markets Mode1}

The efficient markets model is:

$$
P_{i t}=E_{t} P_{i t}^{\star}
$$

Here $P_{i t}$ is the price of a unit of asset $i$ (which may be portfolio $i$ or of index $i$ ) and $P_{i t}^{*}$ is the true or fundamental value corresponding to this asset. $E_{t}$ denotes mathematical expectation conditional on all publicly available information at time $t$. In the application below, $P_{i t}$ is the detrended real stock price index $i$ and $P_{i t}^{*}$ is the detrended present value at time $t$ of dividends represented by the stock price index $i$ starting with time $t$ and into the future. ${ }^{3}$

Now, it should first be recognized that, under this model, for two assets $i$ and $j, \operatorname{Cov}\left(P_{i t}, P_{j t}\right)$ can exceed $\operatorname{Cov}\left(P_{i t}^{\star}, P_{j t}^{\star}\right)$.

It is in fact possible under the efficient markets model ( 1 ) that $P_{\text {it }}$ and $P_{j t}$ can be perfectly correlated with each other even if $P_{i t}^{*}$ and $P_{j t}^{*}$ are perfectly uncorrelated with each other. Suppose that $P_{i t}^{*}$ and $P_{j t}^{*}$ are independent of each other, have the same unconditional mean and unconditional variance and that some information variable $I_{t}$ is available that reveals the sum: $I_{t}=P_{i t}^{*}+P_{j t}^{\star}$. The breakdown of the sum into the components is not available, i.e., the information about the two present values is pooled. By the usual errors-in-variables formula, (and assuming we have subtracted means from all variables) both $P_{i t}$ and $P_{j t}$ will equal $.5 I_{t}$, and hence the two are perfectly correlated. Since the information pooling is positive, the correlation is positive. We can just as well construct an example where the two are perfectly negatively correlated with

${ }^{3}$ Detrending is done differently here than in earlier papers that were criticized for possible spurious trend estimation. 
each other. To do that, we would need only to suppose that $I_{t}$ equals $P_{i t}^{*}$ - $\mathrm{P}_{\mathrm{jt}}^{\star}$, a case of negative information pooling.

Let us arrange the asset prices $P_{i t}, i-1, \ldots . k$, into a k-element vector $P_{t}$, and the fundamental values $P_{i t}^{*}, i=1, \ldots, k$ into another $k$-element vector $P_{t}^{*}$. Then, in vector form, the efficient markets model is

$$
P_{t}=E_{t} P_{t}^{*}
$$

writing $P_{t}^{*}=P_{t}+U_{t}$ where $U_{t}$ is a kxl vector of forecast errors, and using the fact that price dividend ratios at time $t$ are in the information set at time $t$, we know that the vectors $P_{t}$ and $U_{t}$ are uncorrelated. Therefore:

$$
\operatorname{Var}\left(P_{t}^{*}\right)=\operatorname{Var}\left(P_{t}\right)+\operatorname{Var}\left(U_{t}\right)
$$

where $\operatorname{Var}()$ denotes a $\mathbf{k} \times \mathbf{k}$ variance matrix. The $i^{\text {th }}$ diagonal element of the above expression is

$$
\operatorname{Var}\left(P_{i t}^{*}\right)-\operatorname{Var}\left(P_{i t}\right)+\operatorname{Var}\left(U_{i t}\right)
$$

Diagonal elements of $\operatorname{Var}\left(U_{t}\right)$ must be nonnegative because of the positive semidefinite requirement for variance matrices. Therefore

$$
\operatorname{Var}\left(P_{i t}^{*}\right) \geq \operatorname{Var}\left(P_{i t}\right)
$$

This variance inequality was used by LeRoy and Porter (1981) and Shiller (1981), to claim that aggregate stock price indexes appear to be too volatile to accord with the present value models. Essentially, stock price indexes $P_{i t}$ appeared to be more volatile than the fundamentals $P_{i t}^{*}$. The econometric work in these papers was criticized by Flavin (1983), Kleidon 
(1986), Marsh and Merton (1986) and others for the stationarity assumptions or small sample properties of estimators, a point I shall return to below. No one has questioned that (5) is an implication of present value models if the variances shown exist, so we may proceed for the moment under this as sumption.

The $1 j^{\text {th }}$ (off diagonal) element of (4) is

$$
\operatorname{Cov}\left(P_{i t}^{*}, P_{j t}^{*}\right)=\operatorname{Cov}\left(P_{i t}, P_{j t}\right)+\operatorname{Cov}\left(U_{i t}, U_{j t}\right)
$$

This model does not imply that $\operatorname{Cov}\left(P_{i t}^{*}, P_{j t}^{*}\right) \geq \operatorname{Cov}\left(P_{i t}, P_{j t}\right)$ because positive semidefiniteness does not require that the off diagonal elements of $\operatorname{Var}\left(U_{t}\right)$ be nonnegative. $\operatorname{Cov}\left(P_{i t}, P_{j t}\right)$ can exceed $\operatorname{Cov}\left(P_{i t}^{*}, P_{j t}^{\star}\right)$ and be consistent with the model (1) if and only if $\operatorname{Cov}\left(U_{i t}, U_{j t}\right)<0$, a case that may be referred to as the positive information pooling case.

A negative correlation between $U_{i t}$ and $U_{j t}$ may be referred to as a case of positive information pooling because the negative correlation between the error terms implies that there is an advantage in predicting the sum $P_{i t}^{*}+P_{j t}^{*}$ over the separate components $P_{i t}^{*}$ and $P_{j t}^{*}$. The prediction $P_{i t}+P_{j t}$ of $P_{i t}^{*}+P_{j t}^{*}$ has an error whose variance is less than the sum of the variances of $U_{i t}$ and of $U_{j t}$. In this case the information in $P_{i t}$ and $P_{j t}$ may be described as more about a broader aggregate than about either $P_{i t}^{*}$ or $P_{j t}^{*}$. Of course, if the efficient markets model is wrong a negative correlation between $U_{i t}$ and $U_{j t}$ need not have any interpretation in terms of pooling of information.

$$
\text { If } \operatorname{cov}\left(\mathrm{P}_{i t}^{*}, \mathrm{P}_{j t}^{*}\right)<\operatorname{cov}\left(\mathrm{P}_{i t}, \mathrm{P}_{j t}\right)+\operatorname{cov}\left(\mathrm{U}_{i t}, \mathrm{U}_{j t}\right) \text { then } \operatorname{cov}\left(\mathrm{U}_{i t}, \mathrm{P}_{j t}\right)+
$$
$\operatorname{cov}\left(U_{j t}, P_{i t}\right)<0$. This inequality means that the forecast error in the price of one asset tends to be negatively related to the price of the other asset. When one asset has a high price the other asset tends to be 
overpriced relative to fundamentals. This implication of the efficient markets model will be tested in Table 2 below.

\section{Portfolios of Stocks}

Another way of generalizing the original variance inequality (5) to include covariance is to check the condition implied by (1) that: ${ }^{4}$

$$
\operatorname{var}\left(P_{t}^{*}\right)-\operatorname{var}\left(P_{t}\right) \text { positive semidefinite. }
$$

This condition says that for any portfolio of assets (whose prices are elements of $P_{t}$ ) with portfolio price $P_{p t}$ and portfolio fundamental value $P_{p t}^{*}, \operatorname{var}\left(P_{p t}^{*}\right) \geq \operatorname{var}\left(P_{p t}\right), 1 . e_{.}$, it is impossible to construct a portfolio with excess volatility. Now, violation of this condition could happen if $\operatorname{var}\left(P_{t}^{\star}\right)-\operatorname{var}\left(P_{t}\right)$ is neither positive semidefinite nor negative semidefinite, which would mean that some portfolios show excess volatility $\operatorname{var}\left(\mathrm{P}_{\mathrm{pt}}^{\star}\right)<\operatorname{var}\left(\mathrm{P}_{\mathrm{pt}}\right)$ but some portfolios do not. For example, it could be that components of the vector $P_{t}$ show excess volatility but that some portfolios diversify away this excess volatility. Or, it could be that no components of $P_{t}$ show excess volatility, but because covariances between prices $P_{i t}$ and $P_{j t}$ are large relative to covariances between fundamental values $P_{i t}^{\star}$ and $P_{j t}^{\star}$, portfolios can be constructed that show excess volatility. This would be a case where blame for failure of the present value model could be placed squarely on the excess covariances rather than excess variances. Violation of the condition ( $\left.5^{\prime}\right)$ could also happen if $\operatorname{var}\left(P_{t}^{*}\right)-\operatorname{var}\left(P_{t}\right)$ is negative semidefinite. This would mean that all conceivable portfolios show excess volatility. ${ }^{4}$ Note that $\operatorname{var}\left(P_{t}^{*}\right)-\cdot \operatorname{var}\left(P_{t}\right)$ is not necessarily equal to $\operatorname{var}\left(U_{t}\right)$,
except under the null hypothesis. 
We can compute the portfolio welghts that minimize excess volatility, i. e., the vector $x$ that maximizes $x^{\prime}\left(\operatorname{var}\left(P_{t}^{*}\right)-\operatorname{var}\left(P_{t}\right)\right) x$ subject to the restriction that $w x=1$ where $w$ is the $1 \times k$ vector whose elements are all $1 / k$. If a maximum exists, $x^{*}$ indicates the relative importance of excess comovements relative to excess volatility of individual assets.

\section{Individual Stocks}

Suppose we made the vector $P_{t}$ the vector of prices of all stocks, so that $P_{t}$ has thousands of elements, and form the corresponding vectors $P_{t}^{*}$ and $U_{t}$. Then an equally weighted market index $P_{\text {indext }}$ is $w P_{t}$. The variance of the market index is then $1 / k$ times the average variance var $\left(P_{i t}\right)$ plus ( $k-$ $1) / k$ times the average covariance $\operatorname{cov}\left(P_{i t}, P_{j t}\right)$. Since $k$ is very large and since covariances are not negligible relative to variances (the market component is a substantial component of individual stock price variance) the variance of the market index $P_{\text {indext }}$ is approximately equal to the average covariance of individual stocks. Similarly, the variance of the market index fundamental $P_{\text {indext }}^{*}$ is "approximately equal to the average covariance between fundamentals $\operatorname{cov}\left(P_{i t}^{*}, P_{j t}^{*}\right)$. Thus, an observation that indexes are excessively volatile is itself an observation that individual stocks covary too much on average to accord with the efficient markets model. Earlier articles (LeRoy and Porter, 1981, Shiller, 1981) that claimed to find excess volatility of stock market indexes have shown (if they are right) evidence of excess covariance among individual stocks. But these studies did not provide evidence whether there was excess covariance between $U$. K. and U. S. stock prices, or between major subindexes. 


\section{Definitions and Detrending}

The prices used for the econometric work were detrended by dividing by a long moving average of lagged dividends. This kind of detrending was discussed in Campbell and Shiller (1988b) where a long moving average of earnings, rather than of dividends, was used to detrend. Our results were similar if dividends or prices were used in place of earnings in the moving average. Since these long moving averages are fairly smooth and trendlike, dividing price by such a moving average is essentially a method of detrending or of removing low-frequency components. Since only lagged (before time $t$ ) dividends are used, no future information is used to detrend the price per share at time $t$. Thus, certain criticisms made in the literature of the use of variance inequalities in econometric work are obviated. Under various nonstationary models for price and dividend discussed in the literature, the detrended price and detrended $P_{i t}^{*}$ will be stationary stochastic processes. There are of course still potential small sample problems in the use of these inequalities to test the model, which will be addressed below.

Two versions of the present value model are considered here. In version $I$, the discount rate is a constant, equal to the average of the $\log$ of one plus the real return on an investment in the portfolio represented by the index, In version II, the discount rate is a short-term interest rate plus a constant term so that the average discount rate is the same as in version 1 .

The detrended fundamental value $P_{i t}^{*}$ was computed according to: 


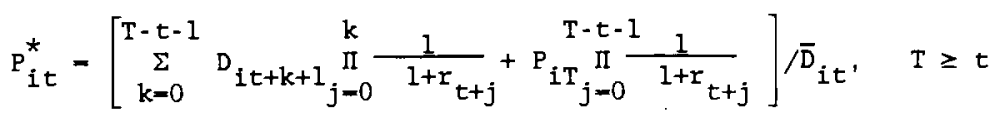

In this formula, the present value of dividends starting with the end of the sample, $t=T$, is proxied by the terminal price $P_{T}$. The moving average of real dividends $\bar{D}_{t}$ that was used to detrend was an exponentially weighted distributed lag on past real dividends, $\bar{D}_{i t}=(1-\rho) \Sigma(k-0, \infty) \rho \mathrm{D}_{i t-k}$. The parameter $\rho$ is taken as $\exp (-R)$ where $R$ is the average of the log of one plus the real return on an investment in the portfolio represented by the index, and $\rho$ is the same as the discount factor in version $I$ of the model. For the U. K., the estimated $\rho$ was 0.935 , for the U. S. it was 0.936 . The "trend" is just the present value formula worked backward in time rather than forward, and the trend as a forecast of the present value of future dividends is just a forecast that the future will be like the past. The trend was computed recursively from an initial condition by $\bar{D}_{i t}-\rho \bar{D}_{1 t-1}+$ $(1-\rho) D_{i t}$. The detrended price $P_{i t}$ is defined as $P_{i t} / \bar{D}_{i t}$ where $P_{i t}$ is the real price index.

This method of detrending, essentially initiated in Campbell and Shiller (1988b), represents a substantial improvement over previous discussions of the alleged excess volatility of stock prices. If we are to consider whether stock prices move too much or comove too much, we are in effect claiming that stocks should be priced differently. It is important to have in mind some simple different pricing rule that shows less movement or less comovement. In my original paper (1981) the alternative was a linear trend line for price. In Mankiw Romer and Shapiro's (1986) it was a proportional to dividend rule for price. These alternatives are less attractive: no one would seriously consider a linear trend or a constant as 
a forecast for fundamentals, and real dividend series are not at all smooth.

As an alternative to using an arbitrary detrending rule, one may compute an optimal forecasting rule for future dividends derived from a cointegrated time series model. This was done in Campbell and Shiller (1988a) using a low-order vector autoregressive model. However, by construction, such a model is incapable of forecasting that the present value of future dividends will depend on a long average of past dividends, since lags are limited by the length of the autoregression. When an $\operatorname{ARIMA}(1,1,1)$ model for aggregate U. S. real dividends was estimated (Shiller 1984), it was found that the optimal forecast of the present value of future dividends did depend on a log exponentially weighted distributed lag on past dividends, like the one used here to detrend.

The present paper aims to make a point in the simplest way possible, without reference to complicated time series models and the linearizations needed to make these serve our purposes when there are time-varying interest rates. The simple detrending rule should be interpreted in this light.

\section{Data}

It was felt that a very long span of data was needed to examine the propositions considered here, data covering many decades. Obtaining many observations by sampling frequently will not give us enough data for our purposes, see for example Shiller and Perron (1986) or Summers (1987). There is a growing recognition of the need for a long time span in financial data, see for example Fama and French (1987) and Schwert (1987).

Finding stock price data with very long time spans is difficult. Most 
individual stocks do not continue for very long in unchanged form. Fama and French examined "survivor" companies that had stayed in business since 1926 , but these companies may be different from others. To obtain really long time series of representative stocks we are forced to deal with portfolios of stocks rather than individual stocks, and these can be represented by stock price indexes. Long time series index data for prices and dividends the U. S. are available back to 1871. Among major countries, only for the United Kingdom was it possible to find a clean, uninterrupted dividend and price series that was nearly as long. Time series on prices and dividends in Japan are available back to 1879 , but there is a break at World War II, after which major holders of stocks, the Zaibatsu, saw their holdings frozen and then sold by the Supreme Command of the Allies in the Pacific. The effect on their net worth of the exchange of nontransferable government bonds for their stock holdings is hard to measure. A similar sale of stocks by occupying authorities occurred in Germany after World War II. It was decided therefore not to use these countries in this study. Of course, omitting them does not completely solve the problem: U. K. and U. S. investors must have been aware of the possibility of confiscation of their holdings should the war have ended differently. There is no way statistically to consider infrequent big events that did not occur in the sample.

The annual U. S. Stock real price index $\mathrm{P}_{\mathrm{USt}}$ 1871-1988 is the December Standard and Poor Composite stock price Index divided by the December producer price index, and the real dividend series $D_{U S t}$ is the corresponding dividends (total for year) divided by the producer price index. The Standard and Poor Composite Stock Price Index and corresponding dividends 
per share adjusted to index, starting 1926, are from Standard and Poor Statistical Service. Before 1926, the dividends per share are from Cowles (1939). The producer price index starting in 1913 is the December all commodities producer price index from the U. S. Bureau of Labor Statistics. For years before 1913, it is linked to the December index of all commodities prices from Warren and Pearson (1935, pages 13-14). For version II of the model, the short rate is the annual return on 4-6 month prime commercial paper, computed from January and July figures under the assumption of a 6 month maturity. These data are from the same sources as in Campbell and Shiller $(1988 a, b)$, and differ from the data used in those papers in that December, rather than January, stock prices and producer price indexes were used. December was chosen to correspond to the specification of the available UK stock price and dividend series.

For the United Kingdom, the real stock price Index $\mathrm{P}_{\text {UKt }} 1919-1986$ is the BZW Equity index (produced by Barclay's de Zoete Wedd) for the end of the year divided by the price deflator 1929 - 1.00 for the year from Friedman and Schwartz (1982), Table 4.9, Column 4, pp. $132-4$ and updated. The BZW Equity Index is an arithmetic market-capitalization-weighted index. The index was created retrospectively for earlier years. Beginning with 1918, the index was constructed from end of year share prices of thirty of the largest publicly quoted British industrial and retail companies, excluding financial, mining and oil companies and companies whose activities were primarily overseas. For years after 1918, changes in the 30 companies were made, in order to make the index as representative as possible of British industry, but in 1962 the index still included 24 of the original 30 companies. Starting with 1963, the index becomes the same as the FT 
Actuaries All Share Index for December. For Version II of the model, the U. K. ominal short-term interest rate is the three-month treasury bill rate, for the end of the year.

For the United States a longer dividend history is avallable than for the United Kingdom. Therefore, different methods were used for the two countries for choosing the initial value for $\bar{D}_{i t 0}$ where to is the beginning of the sample used to compute variance matrices. In the United states, dividend series are available for years back to 1871 . $\overline{\mathrm{D}}_{i \text { to }}$ was therefore taken as $\Sigma(j=1, \ldots, \infty) \rho^{j-1_{D-j}}$ where $D_{1871}$ was used to proxy for real dividends before 1871. In the United Kingdom, the real dividend series begins in 1918, however real price series are available much earlier. ${ }^{5}$ Under the assumption that the average dividend-price ratio was the same before $1918, \overrightarrow{\mathrm{D}}_{\text {UKto }}$ was taken as $\delta \Sigma(j-1, \ldots, \infty) \rho^{j-1_{P_{U K} O-j}}$, where $\delta$ is the average dividend-price ratio 1920-86 and where $P_{U K 1871}$ is used to proxy for prices before 1871. Since a long average smooths over short-term fluctuations, this value for $\bar{D}_{U K t O}$ is likely to be a good proxy for the true value if there is no long term trend in the dividend price ratio, even though $\delta \mathrm{P}_{U K \mathrm{Ut}}$ would be a poor proxy for the dividend in a given year.

\section{$\underline{\text { Results }}$}

Table 1 shows variance matrices for the U.S. and U.K. in expression 3 above. Standard errors, shown in parentheses, are based on stochastic simulations using an estimated model, which is a second order autoregressive

${ }^{5}$ To obtain a price index before 1918, the London and Cambridge Economic Service Index of Industrials [K. C. Smith and G. F. Horne, 1934] was spliced to the DeZoete and Wedd index by multiplying it by the ratio of the indexes in 1918. 
model for each pair of variables whose variance matrix is estimated. ${ }^{6}$ The error terms in the simulations were constructed with a bootstrap method, so that normality was not assumed. Panel A shows the constant real discount rate case, version 1. Panel B shows the time-varying discount rate case, version 2 .

In version 1 , we see from the variance matrices shown that there appears to be not only excess volatility in the individual countries stock markets $\left(\operatorname{var}\left(P_{i t}\right)>\operatorname{var}\left(P_{i t}^{*}\right)\right)$ but also that the stock price variables move together a lot more than do the fundamentals, $\operatorname{cov}\left(P_{i t}, P_{j t}\right)>\operatorname{cov}\left(P_{i t}^{*}, P_{j t}^{*}\right)$. There is no evidence of the positive information pooling that might justify the covariance of prices exceeding that of fundamentals, that is, $\operatorname{cov}\left(U_{i t}, U_{j t}\right)>0$. It was noted above, by viewing Figure 1 , that there is a broad similarity in appearance between the U. K. and U. S. real price series and between the U. K. and U. S. real dividend series. The excess comovement might be described as just the same excess volatility in two closely related countries. The U. S. market shows rather more excess volatility than does the U. K. market, and the portfolio that minimizes excess volatility puts almost all the weight on the U. K. market.

In version 2 , where time varying interest rates are taken into account, there is weaker evidence that $\operatorname{var}\left(P_{i t}\right)>\operatorname{var}\left(P_{i t}^{*}\right)$ in the $U$. $K$. and no evidence for this in the U. S.. The reason is that real interest rates have been quite variable and positively autocorrelated in both countries. A

${ }^{6}$ with other assumed stochastic processes, of course, the uncertainty about these variance matrices may be even higher. For reasons stressed by Kleidon [1986] and others, there may be a bias toward finding excess volatility in small samples. With the lognormal random walk assumption for dividends that Kleidon stressted, there is a tendency for the variance of $P$, to be greater than that of $P_{\text {, }}$, but not so much greater as actually observed in the U. S. See Shiller [1988a], [1989]. 
protracted period of predominantly low or predominantly high real interest rates has, by expression 7 , a substantial cumulated effect on $P_{i t}^{*}$. In version 2 we also no longer find evidence that $\operatorname{cov}\left(P_{1 t}, P_{j t}\right)>\operatorname{cov}\left(P_{i t}^{*}, P_{j t}^{*}\right)$ between the two countries. The fundamentals move together more than do the price variables. Real interest rates behaved broadly similarly in the two countries. In both countries, real rates were high in the 1920's, generally negative or negligibly positive in the late 1930's and 1940's, positive in the late 1950's and early 1960's, negative in the 1970's, and high in the $1980^{\prime} \mathrm{s}$.

Table 2 shows regressions of the forecast error $P_{i t}^{*}-P_{i t}$ onto the price variable $\mathrm{P}_{j \mathrm{t}}$. In panel $\mathrm{A}$, where version $I$ of the model is tested, the coefficient of the price variable is always negative, indicating both excess volatility and excess comovement between the U. K. and the U. S. The coefficient is usually near -1.00 . In the own-country regressions such a value for the coefficient indicates that any movements in the price variable are totally due to forecast error. The coefficient is significant at the $5 \%$ level in both $U$. $K$. and $U$. S. when forecast errors in one country are regressed on the price variable in the same country $(i=j)$. It is also significant at the $5 \%$ level when U. S. forecast errors are regressed on the $U$. K. price variable, but it is not significant when the U. K. forecast errors are regressed on the U. S. price variable. In panel B, we see that forecast errors in one country are regressed on the price variable in that country, the coefficient is substantially negative and significant in both countries. This means that while real interest rate movements are big enough to possibly account for the movements in the stock price variable $P_{1 t}$, the real interest rate movements in fact do not account for the actual 
movements. Simply put, it means that when prices are high they tend also to be high relative to fundamentals. When forecast errors in one country are regressed on the price variable in the other country in panel B, the coefficient is also negative but smaller and statistically insignificant. There is thus a suggestion of excess comovement in the time-varying interest rate case, but there are not enough data to be able to establish this with any authority. 


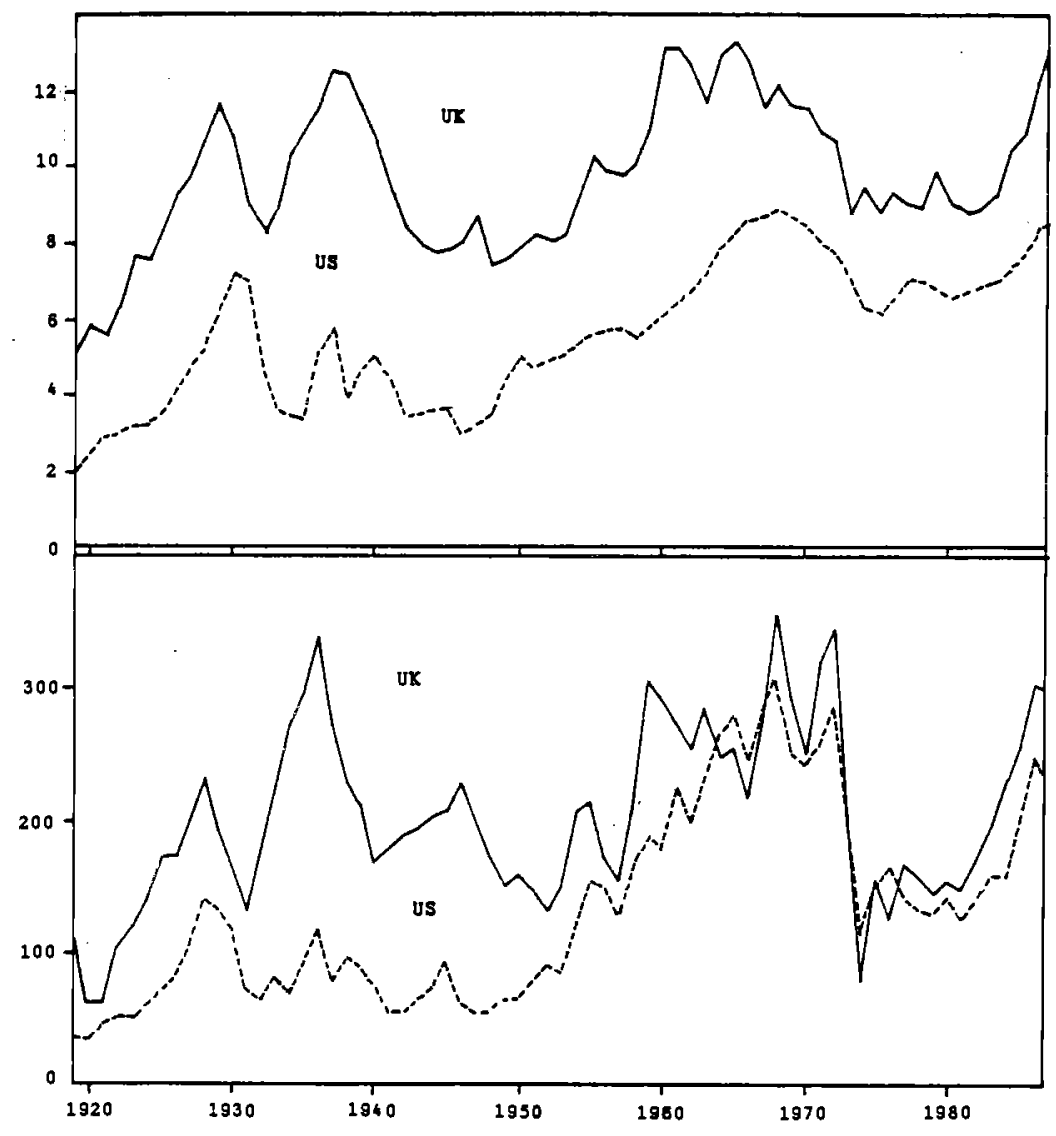

Figure 1. Comparisons of annual real dividends and real prices in the U. K. and the U.S. Upper Panel: Real Dividend Indexes per share, 1919-1987. Lower Panel: Real Price Indexes, year end, 1919-87. See text for source of data. 
Table 1

Variance Matrices

A. Version I: constant discount rate case.

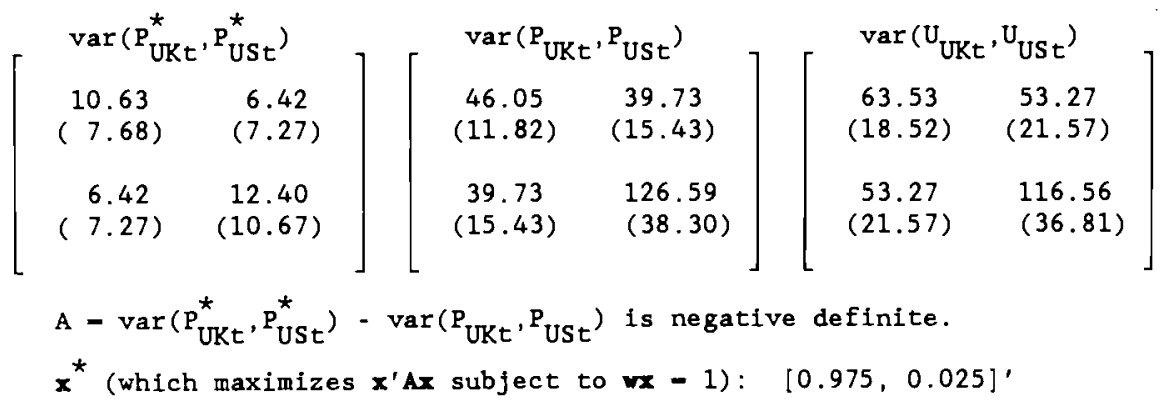

B. Version II: time varying discount rate case.

$$
\left[\begin{array}{cc}
\operatorname{var}\left(P_{U K t}^{*}, P_{U S t}^{*}\right) \\
18.64 & 41.75 \\
(13.41) & (29.67) \\
41.75 & 126.84 \\
(29.67) & (79.66)
\end{array}\right]\left[\begin{array}{cc}
\operatorname{var}\left(P_{U K t}, P_{U S t}\right) \\
46.05 & 39.73 \\
(11.82) & (15.43) \\
39.73 & 126.59 \\
(15.43) & (38.30)
\end{array}\right]\left[\begin{array}{cc}
\operatorname{var}\left(U_{U K t}, U_{U S t}\right) \\
33.38 & 60.97 \\
(7.56) & (20.88) \\
60.97 & 307.41 \\
(21.57) & (114.49)
\end{array}\right]
$$

A $-\operatorname{var}\left(P_{U K t}^{*}, P_{U S t}^{*}\right)-\operatorname{var}\left(P_{U K t}, P_{U S t}\right)$ is neither positive definite nor $x^{*}$ (which maximizes $x^{\prime} A x$ subject to $\left.w x-1\right):(0.057,0.943]^{\prime}$

Note: Figures in parentheses are standard errors estimated by bootstrap montecarlo simulation, based on an estimated VAR(2) model for the 2 -element vector whose variance matrix is estimated, and 1000 replications. 
Table 2

Regression of Forecast Error on Price Variable

$$
P_{i t}^{*}-P_{i t}=a+b P_{j t}+\varepsilon_{t}
$$

A. Version I: constant discount rate case.

\begin{tabular}{|c|c|c|c|c|c|}
\hline i & $\mathbf{j}$ & a & b & $\mathrm{R}^{2}$ & $\sigma_{\epsilon}$ \\
\hline U. $\mathrm{K}$. & U. $\mathbf{K}$. & $\begin{array}{l}23.195 \\
(2.632)\end{array}$ & $\begin{array}{c}-1.074 \\
(-3.504)\end{array}$ & 0.837 & 3.245 \\
\hline $\mathrm{U} . \mathrm{K}$. & U. S. & $\begin{array}{c}7.710 \\
(0.692)\end{array}$ & $\begin{array}{c}-0.348 \\
(-1.063)\end{array}$ & 0.241 & 6.995 \\
\hline U. S. & $\mathrm{U} . \mathrm{K}$. & $\begin{array}{l}20.285 \\
(2.008)\end{array}$ & $\begin{array}{c}-0.924 \\
(-2.638)\end{array}$ & 0.337 & 8.854 \\
\hline U. S. & U. S. & $\begin{array}{l}23.411 \\
(1.827)\end{array}$ & $\begin{array}{c}-0.911 \\
(-2.431)\end{array}$ & 0.902 & 3.402 \\
\hline
\end{tabular}

B. Version II: Time varying discount rate case.

\begin{tabular}{|c|c|c|c|c|c|}
\hline$i$ & $j$ & $\mathbf{a}$ & b & $\mathrm{R}^{2}$ & $\sigma_{\epsilon}$ \\
\hline $\mathrm{U} . \mathrm{K}$. & $\mathrm{U} . \mathrm{K}$. & $\begin{array}{l}15.903 \\
(1.900)\end{array}$ & $\begin{array}{c}-0.660 \\
(-2.267)\end{array}$ & 0.595 & 3.676 \\
\hline U. $\mathrm{K}$. & U. S. & $\begin{array}{r}11.309 \\
(1.069)\end{array}$ & $\begin{array}{r}-0.396 \\
(-1.277)\end{array}$ & 0.597 & 3.693 \\
\hline U. S. & U. $\mathrm{K}$. & $\begin{array}{l}14.759 \\
(1.390)\end{array}$ & $\begin{array}{c}-0.189 \\
(-0.513)\end{array}$ & 0.005 & \\
\hline U. S. & U. S. & $\begin{array}{c}42.96 \\
(3.189)\end{array}$ & $\begin{array}{c}-1.211 \\
(-3.077)\end{array}$ & 0.606 & \\
\hline
\end{tabular}

Note: Estimation method is ordinary least squares. Figures in parentheses are $t$ statistics, corrected for overlapping observations as described in Shiller (1988b). 


\section{REFERENCES}

Bulkley, George, and Ian Tonks, "Are UK Stock Prices Excessively Volatile?" London School of Economics, Financial Markets Group, Autumn 1987.

Campbel1, John Y., and Robert J. Shiller, "Cointegration and Tests of Present Value Models," Journal of Political Economy 95:1062-1088, October 1987.

Campbel1, John Y. and Robert J. Shiller, The Dividend-Price Ratio and Expectations of Future Dividends and Discount Factors," forthcoming, Review of Financial Studies, 1988a.

Campbe11, John Y. and Robert J. Shiller, "The Dividend-Ratio Model and Small Sample Bias," forthcoming, Economics Letters, 1989.

Campbel1, John Y. and Robert J. Shiller, "Stock Prices, Earnings, and Expected Dividends, "Journal of Finance, July, $1988 \mathrm{~b}$.

Cowles, Alfred, Common Stock Indexes, 2nd ed., Principia Press, Bloomington, 1939.

Fama, Eugene F, and Kenneth R. French, "Permanent and Temporary Components of Stock Prices", Center for Research in Securities Prices Working Paper No. 178, University of Chicago, 1986.

Flavin, Marjorie A., "Excess Volatility in the Financial Markets: A Reassessment of the Empirical Evidence," Journal of Political Economy, $91: 929-56,1983$.

French, Kenneth R., G. William Schwert and Robert F. Stambaugh, "Expected Stock Returns and Volatility", Journal of Financial Economics 19:3-29, September 1987.

Friedman, Milton, and Anna J. Schwartz, Monetary Trends in the United States and the United Kingdom. The University of Chicago Press, 1982.

Kleidon, Allan W., "Variance Bounds Tests and Stock Price Valuation Models", Journal of Political Economy 94:953-1001, October 1986.

LeRoy, Stephen F. and Richard D. Porter, "The Present-Value Relation: Tests Based on Implied Variance Bounds", Econometrica 49:97-113, 1981.

Macaulay, Frederic, Some Theoretical Problems Suggested by the Movements of Interest Rates. Bond Yields and Stock Prices in the United States Since 1856 , NBER, New York, 1938.

Mankiw, N. Gregory, David Romer, and Matthew D. Shapiro, "An Unbiassed Reexamination of Stock Market Volatility," Journal of Finance 40:677-87, May 1985.

Marsh, Terry A, and Robert C. Merton, "Dividend Variability and Variance 
Bounds Tests for the Rationality of Stock Market Prices", American Economic Review 76:483-498, June 1986 .

Poterba, James M. and Lawrence H. Summers, "The Persistence of Volatility and Stock Market Fluctuations," American Economic Review 76:1142-1151, December 1986.

Poterba, James M. and Lawrence H. Summers, "Mean Reversion in Stock Prices: Evidence and Implications", unpublished paper, Harvard University, revised March 1987.

Pindyck, Robert S., and Julio J. Rotemberg, "The Excess Co-Movement of Commodity Prices," National Bureau of Economic Research Working Paper No. 2671, July 1988 .

Shiller, Robert J., "Do Stock Prices Move Too Much to be Justified by Subsequent Changes in Dividends?", American Economic Review 71:421-436, June 1981 .

Shiller, Robert J., Market Volatility, forthcoming, M. I. T. Press, 1989.

Shiller, Robert J., "The Probability of Gross Violations of a Present Value Variance Inequality," Journal of Political Economy, 96:1089-92, 1988. (a)

Shiller, Robert J., "A Scott Type Regression Test of the Dividend Ratio Mode1," reproduced, Yale University, 1988. (b)

Shiller, Robert J., "Stock Prices and Social Dynamics", Brookings Papers on Economic Activity 2:457-498, 1984 .

Smith, K. C., and G. F. Horne, "An Index Number of Securities 1867-1914," London and Cambridge Economic Service, Special Memorandum No. 37, June 1934.

Warren, George F., and Frank A. Pearson, Gold and Prices, New York, John Wiley and Sons, 1935. 